\title{
INFLUENCE OF AINb3.5B0.4 GRAIN REFINEMENT ON THE PRECIPITATION OF Fe-RICH INTERMETALLICS IN A SECONDARY AISi7Mg ALLOY
}

\author{
Giulia SCAMPONE, Ozen GURSOY, Riccardo CERATO, Giulio TIMELLI \\ University of Padova, Department of Management and Engineering, Vicenza, Italy, EU, \\ giulia.scampone@phd.unipd.it, yozen.gyursoy@phd.unipd.it, riccardo.cerato@gmail.com, \\ timelli@gest.unipd.it
}

https://doi.org/10.37904/metal.2021.4229

\begin{abstract}
Aluminum-silicon alloys are important materials in foundry to produce light components to be used in the automotive industry for weight saving, reduction of carbon emission from vehicles and air pollution. The mechanical properties of these alloys are strictly related to the final microstructure that can be improved by grain refinement. However, the addition of specific grain refiners can promote the formation of Fe-rich compounds with platelet morphology, which can significantly affect the ductility of the alloy. In the present research, the effect of AINb3.5B0.4 grain refiner on the formation of Fe-rich intermetallics in a secondary AISi7Mg alloy was investigated. Metallographic and image analysis techniques were used to quantitatively investigate the microstructural variations occurring with the addition of grain-refining agent at different cooling rates. The results show that the $\alpha-\mathrm{Fe}$ compounds are the dominant Fe-rich phase in the secondary AISi7Mg alloy. On the other side, the addition of AINb3.5B0.4 grain refiner promotes the precipitation of $\beta$-Fe platelets at the expense of Chinese script $\alpha$-Fe particles. This mechanism is even more evident at higher cooling rates. The AINb3.5B0.4 grain refinement significantly affects the number density of $\beta$-Fe compounds but it does not influence their dimensions. The size of $\beta$-Fe particles appears to be sensitive to the change of the cooling rate; higher cooling rate refines the microstructural scale as well as the Fe-rich platelets. The addition of AlNb3.5B0.4 produces a fine and uniform grain structure throughout the alloy and this effect is more pronounced in the slowly solidified material. Increasing the cooling rate, lower amounts of grain refiner are needed to produce a uniform grain size throughout the casting.
\end{abstract}

Keywords: Aluminum alloy, Fe-rich intermetallic, niobium, boron, microstructure

\section{INTRODUCTION}

After solidification of Al-Si alloys, coarse and columnar grain structure is usually observed unless the melt solidifies with a high cooling rate. Coarse grains may result in many types of defects, reduction of yield strength and ductility. Fine and equiaxed grain structure can be produced by the addition of a number of elements, such as $\mathrm{Ti}, \mathrm{B}, \mathrm{Zr}$, Nb into the melt. The addition of the grain refiner increases the number of heterogeneous nucleation sites in the molten metal; these are usually aluminides or borides formed by peritectic reaction, and the nucleation density is thus increased during the solidification resulting in grain refined microstructure. It is reported that fine and equiaxed grain structure guarantees better surface finish, advanced mechanical properties, finer microporosity, better dispersion of secondary phases, improved feeding and fluidity [1].

In the current foundry practice, chemical grain refinement is commonly accomplished by the introduction of master alloys into the molten bath. Grain refiners usually contain $\mathrm{Ti}$ and/or $\mathrm{B}$ with various $\mathrm{Ti} / \mathrm{B}$ weight ratios, such as Al-5Ti, Al-4B, Al-5Ti-1B, Al-3Ti-3B, Al-1Ti-3B. Although there is still a great discussion about the efficiency of those master alloys, the general conclusion is that the effect of grain refinement is more remarkable by using $\mathrm{Al}-\mathrm{B}$ or $\mathrm{Al}-\mathrm{Ti}-\mathrm{B}$ with a Ti/B ratio lower than $1: 1$ because of the interaction between $\mathrm{Ti}$ and 
Si reducing the effective quantity of $\mathrm{Al}_{3} \mathrm{Ti}$ and $\mathrm{TiB}_{2}$ nucleants [2]. A new generation of master alloys, such as $\mathrm{Al}-\mathrm{Zr}, \mathrm{Al}-\mathrm{Ti}-\mathrm{C}, \mathrm{Al}-\mathrm{Nb}-\mathrm{B}$, are used in grain refinement where $\mathrm{Al}_{3} \mathrm{Zr}, \mathrm{TiC}, \mathrm{Al}_{3} \mathrm{Nb}$ and $\mathrm{NbB}_{2}$ phases are the main nucleants of $\alpha-A l$ phase. The $\mathrm{Al}_{3} Z \mathrm{Z}$ phase has been found to be less effective than the $\mathrm{Al}_{3} \mathrm{Ti}$ phase on the grain refinement [3]. Although Al-Ti-C master alloy shows lower agglomeration tendency with respect to Al-Ti-B system, the TiC phase might be faded because it is thermodynamically unstable and can be poisoned by $\mathrm{Si}$ [4]. The $\mathrm{NbB}_{2}$ phase is much more stable than $\mathrm{TiB}_{2}$ particles, showing therefore greater efficiency on grain refinement [5]. In recent years, lanthanides, such as $\mathrm{La}, \mathrm{Ce}, \mathrm{Gd}$, have shown the potency of grain refinement of Al-Si alloys too. On the other hand, they have a matter of cost in use and tend to fade [6].

Grain refiner can interact with alloying elements and impurities present in the initial alloy. Several investigations conclude that $\mathrm{Ti}$ interacts with minor additions and impurities, such as $\mathrm{Sr}, \mathrm{Zr}, \mathrm{Cu}$, and $\mathrm{Fe}$ as well as with $\mathrm{Si}$, resulting in a coarser $\alpha$-Al structure [7-10]. Among all impurities, iron is one of the most harmful in Al-Si foundry alloys, especially in the form of $\beta-\mathrm{Al}_{5} \mathrm{FeSi}$ platelets, which increase the alloy embrittlement. The sharp edges of $\beta$ phase generate high-stress concentrations, resulting in the formation of cracks and the decrease of mechanical properties [11].

Understanding the effect of grain refiner addition on the formation of Fe-rich compounds is of great importance to improve the final casting quality. Previous works focused on the influence of AITi5B, AITi10, Al5B grain refiners on the Fe-rich phases $[12,13]$. On the other side, the studies on the effect of $\mathrm{Nb}-\mathrm{B}$ inoculant on the precipitation of iron-rich particles in Al-Si alloys are limited.

This study aims to analyse the influence of different levels of $\mathrm{Al}-3.5 \mathrm{Nb}-0.4 \mathrm{~B}$ grain refiner on the precipitation of Fe-rich intermetallics in secondary Al-7Si-0.3Mg alloy.

\section{EXPERIMENTAL PROCEDURE}

\subsection{Casting procedure}

A secondary AlSi7Mg cast alloy (EN AB-42000) in the form of commercial ingots was used as the base alloy and its chemical composition is shown in Table 1. An AlNb3.5B0.4 master alloy in rod shape was used as a grain refiner and added at two different levels ( 0.3 and $1.4 \mathrm{wt} \%$ ) in order to obtain nominal $\mathrm{Nb}$ contents of 100 and $500 \mathrm{wt}$. ppm $\mathrm{Nb}$ and nominal B levels of 13 and $55 \mathrm{wt}$. ppm B. The experimental chemical composition of the grain refined alloy is listed in Table 1. About $3.5 \mathrm{~kg}$ charge of AlSi7Mg alloy was melted at $750{ }^{\circ} \mathrm{C}$ in a SiC crucible in a resistance-heated furnace. The molten bath was gently skimmed and stirred before each addition, and it was held at $750{ }^{\circ} \mathrm{C}$ for $30 \mathrm{~min}$ to ensure the complete dissolution of the grain refiner addition. The melt was poured at $750{ }^{\circ} \mathrm{C}$ into two different boron nitride-coated steel moulds: a cylindrical-shaped die with an inner diameter of $20 \mathrm{~mm}$ and height of $100 \mathrm{~mm}$, and a truncated conical cup with a lower diameter of $45 \mathrm{~mm}$, an upper diameter of $70 \mathrm{~mm}$ and height of $60 \mathrm{~mm}$. Both dies were preheated at $550^{\circ} \mathrm{C}$. The cylindrical-shaped mould provides a higher cooling rate of $1.3^{\circ} \mathrm{C} / \mathrm{s}$, while the truncated conical cup provides a lower cooling rate of $0.1^{\circ} \mathrm{C} / \mathrm{s}$. No degassing treatment was performed before casting operations.

Table 1 Chemical composition ( $w t \%)$ of the investigated alloys

\begin{tabular}{|c|c|c|c|c|c|c|c|c|c|c|}
\cline { 2 - 10 } \multicolumn{1}{c|}{} & $\mathrm{Al}$ & $\mathrm{Si}$ & $\mathrm{Fe}$ & $\mathrm{Cu}$ & $\mathrm{Mn}$ & $\mathrm{Mg}$ & $\mathrm{Zn}$ & $\mathrm{Ti}$ & $\mathrm{Nb}$ & $\mathrm{B}$ \\
\hline AlSi7Mg (base alloy) & Bal. & 7.36 & 0.43 & 0.055 & 0.29 & 0.35 & 0.05 & 0.021 & 0 & 0.0001 \\
\hline $\begin{array}{c}\text { AlSi7Mg + 0.3 wt\% } \\
\text { AlNb3.5B0.4 }\end{array}$ & Bal. & 7.34 & 0.43 & 0.055 & 0.29 & 0.35 & 0.05 & 0.021 & 0.0106 & 0.0013 \\
\hline $\begin{array}{c}\text { AISi7Mg + 1.4 wt\% } \\
\text { AlNb3.5B0.4 }\end{array}$ & Bal. & 7.25 & 0.44 & 0.053 & 0.30 & 0.31 & 0.05 & 0.020 & 0.0504 & 0.0055 \\
\hline
\end{tabular}




\subsection{Metallographic characterization}

The cylindrical sample was transversely cut at $25 \mathrm{~mm}$ from the bottom surface, while the sample with a cooling rate of $0.1^{\circ} \mathrm{C} / \mathrm{s}$ was sectioned longitudinally in half to extract a surface for the microstructural investigation. Both samples were then mounted, ground, and polished according to standard metallographic techniques. Optical (OM) and scanning electron microscopes (SEM) were used to measure the secondary dendrite arm spacing $\Lambda_{2}$ and to characterize the distribution of the size and morphology of the Fe-rich phases in the microstructure. To obtain a statistical average of the distribution, the series of different micrographs of each specimen were taken covering a region of interest of $8 \mathrm{~mm}^{2}$; each measurement included more than 400 particles.

To improve the contrast between the Fe-rich phases and other phases in the microstructure, the polished samples were chemically etched in an aqueous sulphuric acid solution at $70{ }^{\circ} \mathrm{C}\left(20\right.$ vol\% $\mathrm{H}_{2} \mathrm{SO}_{4}$ and 80 vol\% $\mathrm{H}_{2} \mathrm{O}$ ). For the measurement of the grain size, the polished specimens were firstly etched in a $\mathrm{CuCl}_{2}$ solution (30 vol\% $\mathrm{CuCl}_{2}$ and 70 vol\% $\mathrm{H}_{2} \mathrm{O}$ ) and then immersed in nitric acid solution ( 86 vol\% $\mathrm{HNO}_{3}$ and $14 \mathrm{vol} \% \mathrm{HF}$ ). The grain size was measured using the intercept method, according to ASTM standard E112-12.

\section{RESULTS AND DISCUSSION}

Figure 1 shows the typical microstructure of AISi7Mg alloy after the addition of AINb3.5B0.4 grain refiner. In general, the microstructure of both AlSi7Mg alloy and grain refined AlSi7Mg alloys consists of a primary phase, a-Al solid solution in the form of dendrites, and a eutectic mixture of aluminum and silicon. Intermetallics compounds, such as $\mathrm{Fe}$ - and $\mathrm{Mg}$-rich intermetallics, are also observed. The Fe-rich compounds show needlelike or Chinese script morphology. After $1.4 \mathrm{wt} \%$ AINb3.5B0.4 addition, polygonal $\mathrm{Nb}$-rich particles are observed in the microstructure, especially at a lower cooling rate (see Figure 1).

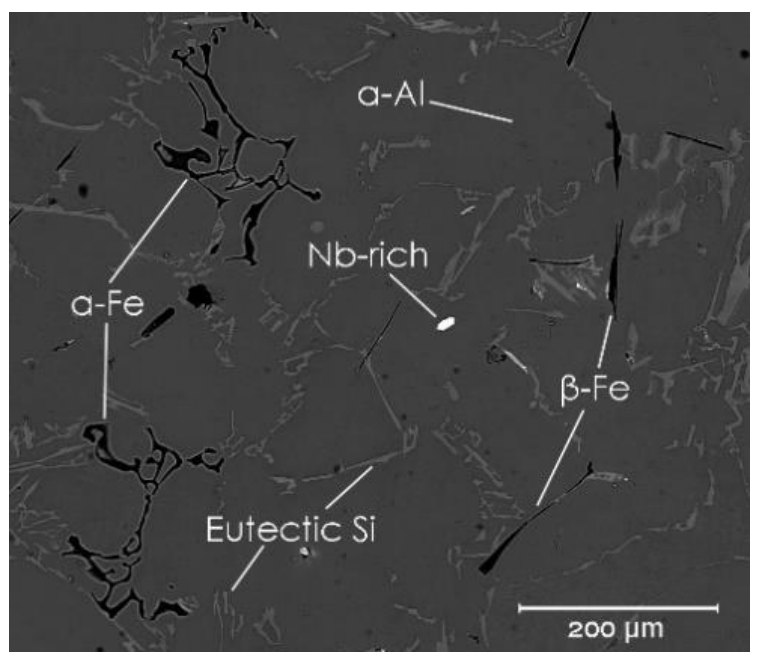

Figure 1 Backscattered SEM micrograph of AISi7Mg alloy after AINb3.5B0.4 grain refinement

For both casting geometries, the scale of the microstructure was evaluated by means of $\Lambda_{2}$ measurements. As expected, the casting geometry of the samples significantly affected the cooling rate, which varied in the range of 36 and $72 \mu \mathrm{m}$. The alloy solidified at a higher cooling rate, i.e. $1.3^{\circ} \mathrm{C} / \mathrm{s}$, showed a microstructure scale with $\Lambda_{2}$ values of $36 \pm 3 \mu \mathrm{m}$. On the other side, the alloy solidified at a lower cooling rate, i.e. $0.1{ }^{\circ} \mathrm{C} / \mathrm{s}$, showed $\Lambda_{2}$ value of $72 \pm 5 \mu \mathrm{m}$.

Figure 2 shows the microstructures of the AISi7Mg and the grain refined AISi7Mg alloys at different cooling conditions. In the AlSi7Mg alloy, the $\alpha-F e$ phase is the dominant phase among the Fe-rich compounds independently of the cooling rate. The addition of AINb3.5B0.4 grain refiner promotes the formation of needlelike Fe-rich compounds whose size is strongly affected by the cooling rate. 


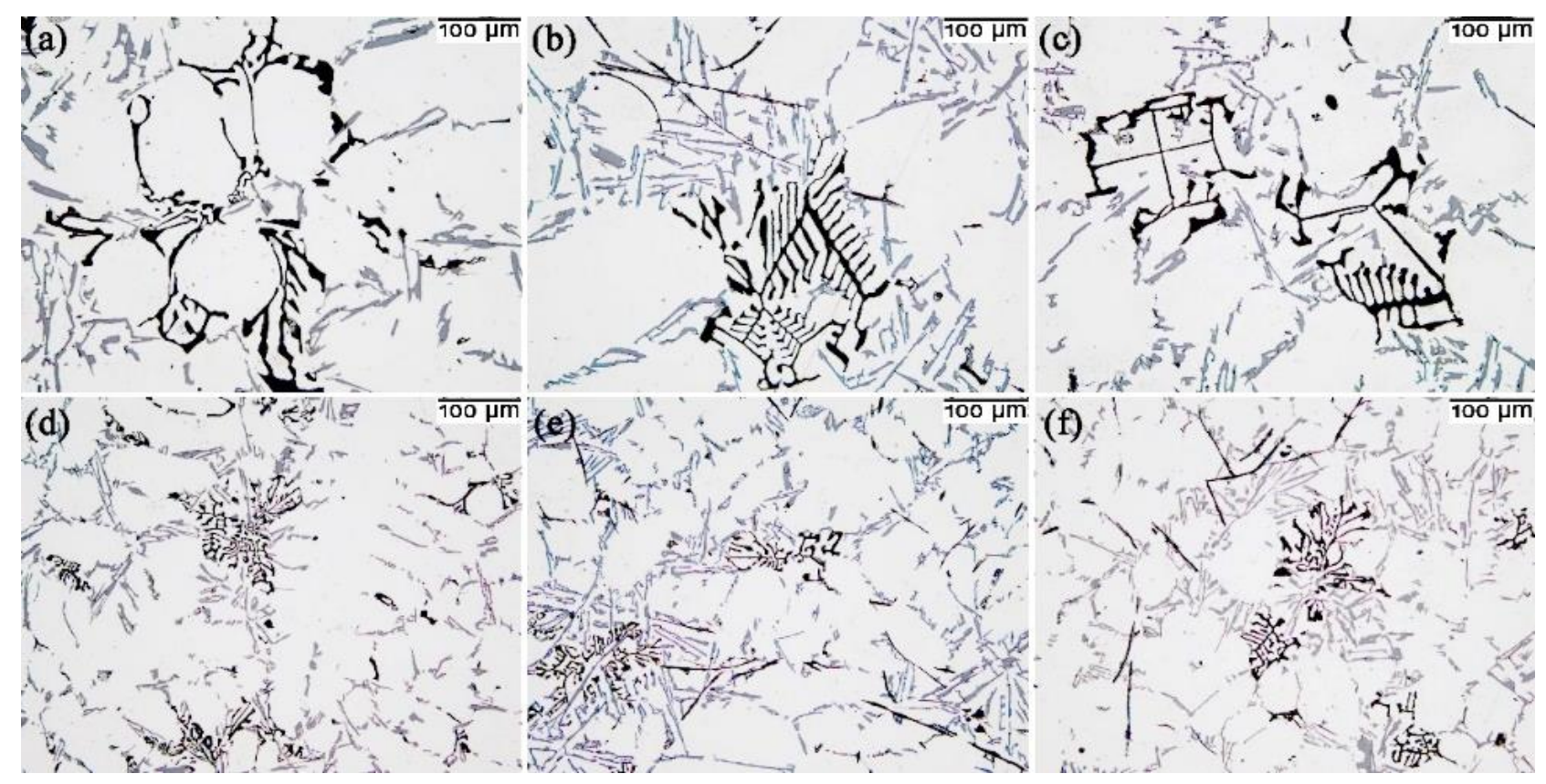

Figure 2 Typical etched microstructures of $(\mathbf{a}, \mathbf{d})$ the AISi7Mg alloy and the grain refined AISi7Mg alloys after (b, e) 0.3 and (c, f) 1.4 wt. \% AINb3.5B0.4 additions. The micrographs correspond to specimens solidified at

(a-c) 1.3 and (d-f) $0.1^{\circ} \mathrm{C} / \mathrm{s}$ cooling rate

Figure 3 presents the statistical analysis of the size and number density of $\beta$-Fe particles in the AISi7Mg alloy at various AINb3.5B0.4 levels and solidified at different cooling rates. Upon increasing the cooling rate in the AISi7Mg alloy, the length of $\beta$-Fe particles with the maximum frequency shifts to lower values and the absolute value of the maximum frequency increases. The average length moves from about 35 to $17 \mu \mathrm{m}$ at lower and higher cooling rates, respectively. Similar behaviour can be observed for the number density of the $\beta$-Fe phase (Figure 3c). These results are in agreement with the findings from Rakhmonov et al. [12]. When the cooling rate increases, the time for intermetallic particles to grow and coarsen decreases because the nucleation temperature of the $\beta-F e$ phase is displaced toward lower temperatures, resulting in smaller and shorter Ferich compounds.

This phenomenon is even more evident after the AINb3.5B0.4 grain refinement. The addition of Nb-B inoculant emphasizes the precipitation of $\beta$-Fe particles but does not significantly affect the average size of the $\beta$-Fe needles (Figures $3 \mathbf{a}$ and $\mathbf{b}$ ).
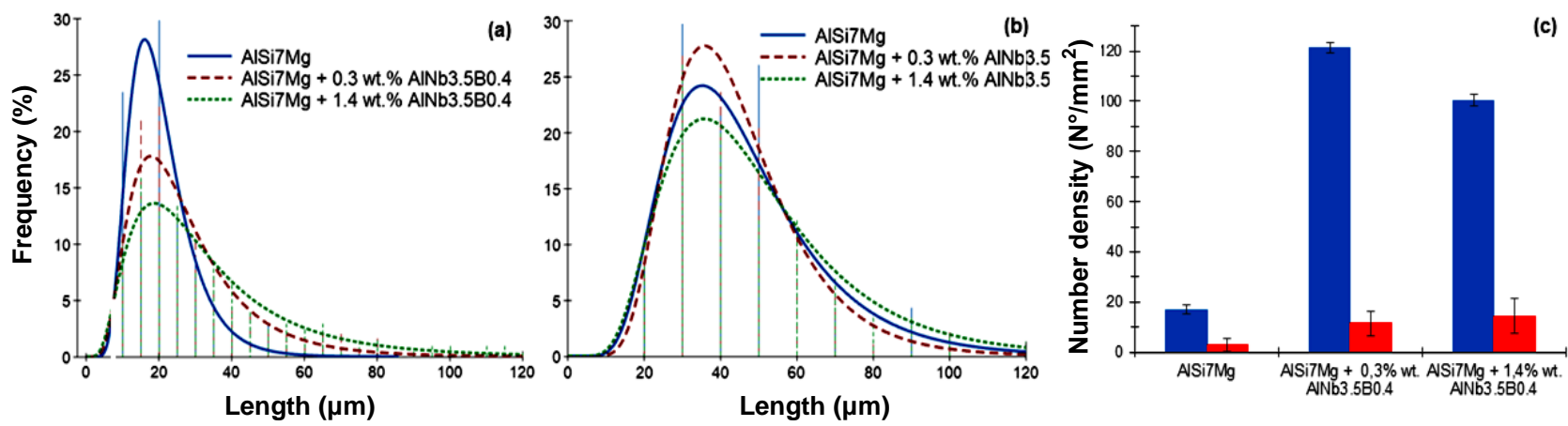

Figure 3 Distributions of the length of $\beta$-Fe particles in the AISi7Mg alloy and grain refined AISi7Mg alloys solidified at different cooling rates: (a) lower and (b) higher (lognormal fitting curves are drawn).(c) Number density of $\beta-F e$ particles as function of the AINb3.5B0.4 level and cooling rate 
Figure 4 shows the area fraction of both $\alpha-\mathrm{Fe}$ and $\beta$-Fe phases as a function of the AINb3.5B0.4 level and the cooling rate. In the AISi7Mg alloy, the $\alpha$-Fe phase appears as the main Fe-rich phase regardless of the cooling rate. In fact, the area fraction of the $\alpha$-Fe phase is higher than $1.28 \%$ and the area fraction of the $\beta$-Fe phase is lower than $0.065 \%$ at both cooling rates. This result can be explained considering the cooling rate and the chemical composition of the AlSi7Mg alloy. The $\mathrm{Mn} / \mathrm{Fe}$ ratio is 0.68 , higher than 0.5 , which is the critical value to suppress the formation of the $\beta$-Fe compounds [14]. This ratio is almost the same also in the refined alloys. It can be therefore assumed that the addition of AINb3.5B0.4 grain refiner promotes the precipitation of $\beta-\mathrm{Fe}$ phase-

Either in the AISi7Mg alloy or in the grain refined AISi7Mg alloys, the Fe-rich compounds, both $\alpha$ - and $\beta$-Fe phases, are well distributed throughout the microstructure, comprising about $1.5 \pm 0.3 \%$ of the total investigated area. As previously mentioned, the formation of different types of iron intermetallics depends on the cooling rate and the chemical composition of the alloy. At $1.3^{\circ} \mathrm{C} / \mathrm{s}$, the area fraction of the $\alpha-F e$ phase in the AlSi7Mg alloy corresponds to $1.297 \%$ and this value decreases to 0.834 and $1.025 \%$ in the alloys modified with 0.3 wt $\%$ and $1.4 \mathrm{wt} \%$ AINb3.5B0.4, respectively. At $0.1{ }^{\circ} \mathrm{C} / \mathrm{s}$, the area fraction occupied by $\beta$-Fe phase increases from $0.050 \%$ in the AISi7Mg alloy to $0.189 \%$ and $0.267 \%$ after the grain refinement with $0.3 \mathrm{wt} \%$ and $1.4 \mathrm{wt} \%$ AINb3.5B0.4, respectively. It must be noted that the addition of AINb3.5B0.4 grain refiner increases the precipitation of $\beta-\mathrm{Fe}$, especially at high cooling rates. Rakhmonov et al. [13] suggested that the limited precipitation of $\beta-\mathrm{Fe}$ in the AlSi7Mg alloy is related to higher undercooling required for the nucleation of this phase. In contrast, the presence of heterogeneous sites, such as $\mathrm{TiB}_{2}$ particles in the refined alloy, facilitates the $\beta$-Fe precipitation at low undercooling. Moreover, a greater undercooling reduces the Fe content involved in the crystallization of $\alpha$-Fe phase and increases the level of Fe available for $\beta$-Fe formation. In this study, the addition of $\mathrm{Nb}-\mathrm{B}$ inoculant promotes the formation of particles which lead to the heterogenous nucleation of the $\beta$-Fe phase. Since Ti content in both base and refined alloys is low, $\mathrm{Ti}_{2} \mathrm{~B}$ particles, which may be formed in a small amount, cannot significantly affect the precipitation of $\beta-\mathrm{Fe}$.
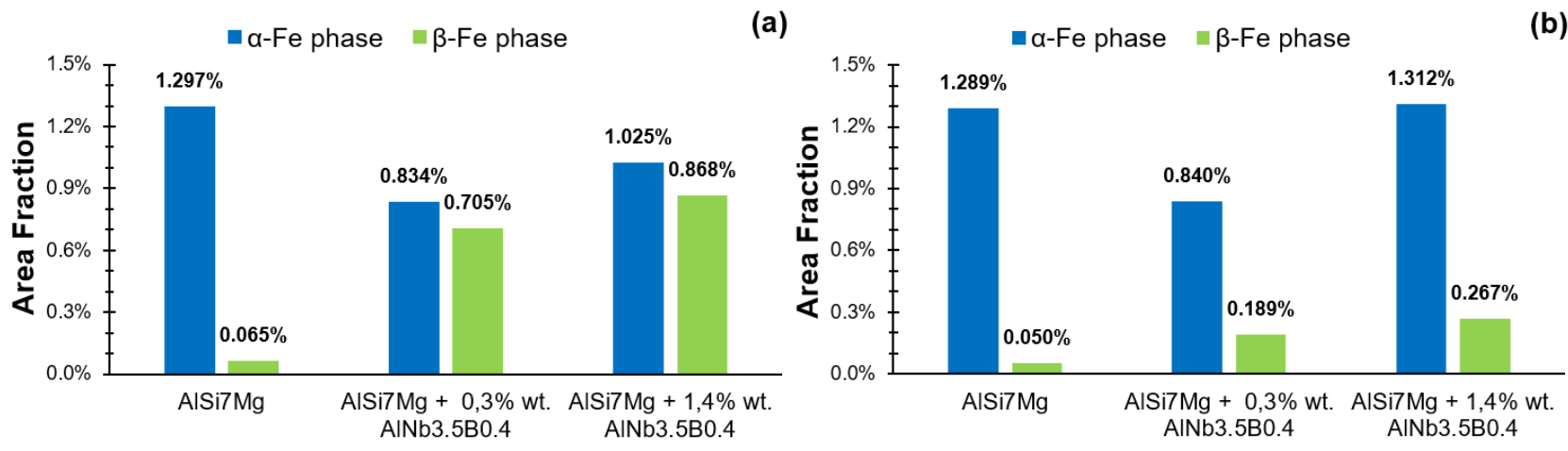

Figure 4 Area fraction of $\alpha-F e$ and $\beta$-Fe particles in the whole Fe-rich compounds in the experimental alloys solidified at (a) higher and (b) lower cooling rate

Figure 5 shows the effect of AINb3.5B0.4 grain refinement on the grain structure of AlSi7Mg alloy at different cooling rates. In general, the AlSi7Mg alloy shows coarser grains respect to grain refined AISi7Mg alloys. Upon increasing the cooling rate from 0.1 to $1.3^{\circ} \mathrm{C} / \mathrm{s}$, the average grain sizes moved from $2470 \pm 320 \mu \mathrm{m}$ to $1650 \pm$ $90 \mu \mathrm{m}$ in the AISi7Mg alloy. The additions of $\mathrm{Nb}-\mathrm{B}$ inoculant progressively reduced the grain size. Regardless of the cooling rate, equiaxed grains with a size of $320 \pm 30 \mu \mathrm{m}$ were obtained after $1.4 \mathrm{wt} \%$ AINb3.5B0.4 addition. These results are in agreement with the previous study of Bolzoni et al. [15], where it was demonstrated that $\mathrm{Nb}$-rich compounds act like heterogeneous substrates for the refinement of Al-Si foundry alloy and make the final grain size less sensitive to the cooling rate. 


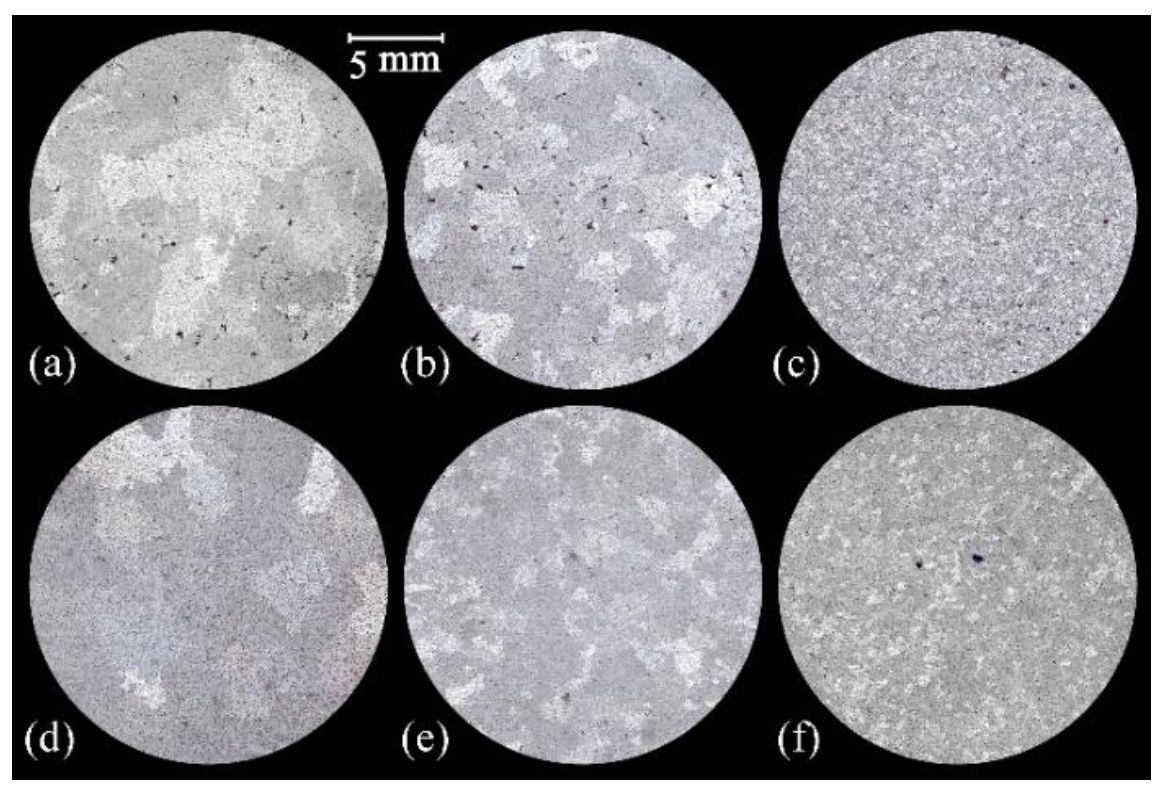

Figure 5 Grain structure of Al7SiMg alloy after (a, d) 0 wt $\%$, (b, e) 0.3 wt $\%$ and (c, f) 1.4 wt $\%$ AINb3.5B0.4 additions. The macrographs refer to different cooling rates during solidification: (a-c) 0.1 and (d-f) $1.3{ }^{\circ} \mathrm{C} / \mathrm{s}$.

\section{CONCLUSION}

In the present work, the influence of AINb3.5B0.4 grain refinement on the precipitation of Fe-rich compounds was studied in a secondary AISi7Mg alloy. The following conclusions can be drawn:

- The addition of AINb3.5B0.4 grain refiner increases the density of polygonal $\mathrm{Nb}$-rich particles in the microstructure.

- The precipitation of $\alpha-\mathrm{Fe}$ and $\beta$-Fe compounds is largely affected by the cooling rate and the initial chemical composition of the alloy. The presence of $\mathrm{Nb}-\mathrm{B}$ promotes the formation of $\beta$-Fe particles, especially at higher cooling rates.

- $\quad$ After AINb3.5B0.4 grain refinement, the content of Nb-B does not significantly affect the size of the $\beta$-Fe particles, which appear finer at high cooling rates.

- The difference in grain size associated with the different cooling rates is suppressed after the addition of $1.4 \mathrm{wt} \%$ AlNb3.5B0.4.

\section{ACKNOWLEDGEMENTS}

\section{This work wasdeveloped with the financial support of Fondazione Cassa di Risparmio di Padova e} Rovigo (CariPaRo).

\section{REFERENCES}

[1] QUESTED, T.E. Understanding mechanisms of grain refinement of aluminum alloys by inoculation. Materials Science and Technology. 2004, vol. 20, no. 11, pp. 1357-1369.

[2] SPITTLE, J.A. Grain refinement in shape casting of aluminum alloys. International Journal of Cast Metals Research. 2006, vol. 19, no. 4, pp. 210-222.

[3] EBRAHIMI, S.S., EMAMY, M. Effects of Al-5Ti-1B and Al-5Zr master alloys on the structure, hardness and tensile properties of a highly alloyed aluminum alloy. Materials \& Design. 2010, vol. 31, no. 1, pp. $200-209$.

[4] MOHANTY, P.S., GRUZLESKI, J.E. Grain refinement of aluminum by TiC. Scripta Metallurgica et Materialia. (United States). 1994, vol. 31, no. 2. 
[5] NOWAK, M., BOLZONI, L., BABU, N.H. Grain refinement of Al-Si alloys by Nb-B inoculation. Part I: Concept development and effect on binary alloys. Materials \& Design. 2015, vol. 66, pp. 366-375.

[6] GURSOY, O., TIMELLI, G. Lanthanides: A focused review of eutectic modification in hypoeutectic Al-Si alloys. Journal of Materials Research and Technology. 2020, vol. 9, no. 4, pp. 8652-8666.

[7] RAO, A.A., MURTY, B.S., CHAKRABORTY, M. Role of zirconium and impurities in grain refinement of aluminum INith Al-Ti-B. Materials science and technology. 1997, vol. 13, no. 9, pp. 769-777.

[8] SAMUEL, A.M., DOTY, H.W., VALTIERRA, S., SAMUEL, F.H. Intermetallic precipitation in rare earth-treated A413. 1 alloy: A metallographic study. International Journal of Materials Research. 2018, vol. 109, no. 2, pp. $157-$ 171.

[9] SPITTLE, J.A., SADLI, S. The influence of zirconium and chromium on the grain-refining efficiency of Al-Ti-B inoculants. Cast Metals. 1995, vol. 7, no. 4, pp. 247-253.

[10] SAMUEL, A.M., DOTY, H.W., VALTIERRA, S., SAMUEL, F.H. Effect of grain refining and Sr-modification interactions on the impact toughness of Al-Si-Mg cast alloys. Materials \& Design. 2014, vol. 56, pp. $264-273$.

[11] TAYLOR, J. A. Iron-containing intermetallic phases in Al-Si based casting alloys. Procedia Material Science. 2012, no. 1, pp. 19-33.

[12] RAKHMONOV, J., TIMELLI, G., BONOLLO, F., ARNBERG, L. Influence of grain refiner addition on the precipitation of Fe-rich phases in secondary AISi7Cu3Mg alloys. International Journal of Metal Casting. 2017, vol. 11, no. 2, pp. 294-304.

[13] RAKHMONOV, J., CORRADIN, G., TIMELLI, G., LIU, H. Comparison of the effects of Al-5B and Al-5Ti-1B grain refiners on the formation of Fe-rich phases in secondary Al-7Si-3Cu-0.3Mg alloys. In: Proceedings of the $5^{\text {th }}$ Decennial International Conference on Solidification Processing. Old Windsor, July 2017.

[14] JI, S., YANG, W., GAO, F., WATSON, D., FAN, Z. Effect of iron on the microstructure and mechanical property of Al-Mg-Si-Mn and Al-Mg-Si diecast alloys. Materials Science and Engineering: A. 2013, vol. 564, pp. 130-139.

[15] BOLZONI, L., NOWAK, M., HARI BABU, N. On the effect of Nb-based compounds on the microstructure of Al12Si alloy. Materials Chemistry and Physics. 2015, vol. 162, pp. 340-345. 